\title{
Skull fracture and the diagnosis of abuse
}

\author{
C J HOBBS
}

Department of Paediatrics and Child Health, St James's University Hospital, Leeds

SUMMARY Eighty nine children under 2 years of age with skull fracture were studied retrospectively-29 children with definite non-accidental injury serially recorded by the Departments of Paediatrics and Forensic Medicine, and 60 children consecutively admitted to hospital with skull fractures after accidents. There were 20 deaths including 19 among abused children. Multiple injuries and an inadequate-history assisted in diagnosing abuse. Fracture characteristics found considerably more often in abused children were: multiple or complex configuration; depressed, wide, and growing fracture; involvement of more than a single cranial bone; non-parietal fracture; and associated intracranial injury including subdural haematoma. No fractures measuring more than $5.0 \mathrm{~mm}$ on presentation were found after accidents, but 6 of these 'growing fractures' were found in abused children. Accidents usually resulted in single, narrow, linear fractures most commonly of the parietal, with no associated intracranial injury. The results suggest that in skull fracture in young children where a minor fall is alleged, it is possible to recognise abuse by consideration of the fracture alone.

Descriptions of physical abuse of children have emphasised the importance of various injuries including fractures. Current experience of abuse is that children sustain fewer of the recognised features, and paediatricians are expected to adjudicate on injuries that are single or minor. A difficult injury to assess is fracture of the skull, and published experience offers limited help. This study provides guidelines for the recognition of abuse in skull fracture from an analysis of 89 children, 29 of whom were abused.

\section{Children studied}

There were 49 boys and 40 girls aged under 2 years.

Abuse. The child abuse team in Leeds received 754 referrals for possible abuse between 1977 and 1982 inclusive. Definite physical abuse or non-accidental injury was diagnosed in 338 cases, and of these a total of 16 children were identified with skull fracture. One further case was added from 1983. Radiographs were obtained for 16 children, including 6 fatal cases. An additional 13 children, all with fatal head injuries and skull fracture after abuse, were identified through the Department of Forensic Medicine of Leeds University. With the inclusion of forensic cases the total group of 29 was inevitably biased toward severe abuse, with 19 fatal cases.
The diagnosis of abuse relied on the history and clinical findings. The history in 19 cases was of a minor fall from a few feet at most. In one case it was claimed that a door had been opened and the child's head had been struck inadvertently. In the remainder, the history was confused, unclear, or unrelated to the injuries. Histories were frequently changed or adjusted when further information was sought, and discrepancies between parents were often noted. In at least 10 cases a full confession was later made to the police.

The diagnosis of abuse was assisted by the presence of multiple injuries characteristic of abuse in 27 of the children, including 14 children with other fractures and 22 with multiple bruises. Three children were grossly malnourished. By contrast other injuries and malnutrition were not found in the accident cases.

Accidents. A total of 75 children consecutively admitted to the two major teaching hospitals in Leeds over a five year period with skull fracture after accepted accidents were identified. Radiographs were traced for 60 of these children. Seven cases of birth trauma or road traffic accident were excluded as confusion with abuse seemed unlikely. Fifteen children had fallen from a raised surface such as a table, worktop, or shelf; 8 had more severe falls (including 7 who fell downstairs and one who 
fell from a first floor window); and a further 8 were injured while running or playing. Only one child sustained a skull fracture from a fall from a settee or surface of equivalent height. Thirteen babies were dropped by a parent or older sibling, and three were injured when the person holding them fell. There were three falls from carrycots or prams and two unspecified falls.

In 15 children, the parent delayed seeking medical advice after the accident, attending hospital only after the discovery of a swelling on the child's scalp. Ellis ${ }^{1}$ has drawn attention to similar swellings, claiming that they were due to leakage of cerebrospinal fluid associated with parietal fracture, and in many of his cases there was delay in presentation. In 7 of the 15 cases, the parent failed to recall the incident that could have accounted for the injury. Many of these were understandably viewed with suspicion and referred to the child abuse team, but in every case it was considered that either the accident had been unwitnessed or that a minor injury had been forgotten when the child seemed unhurt.

A total of 15 children with accidental fractures were referred with suspicion of abuse prompted by delayed presentation, adverse social factors, or unease about the circumstances of the injury. All were accepted as accidents after careful paediatric and social work assessment. Only one child in the accident group is known to have suffered abuse at a later date, but it is uncertain whether the original injury arose as a result of abuse.

Radiographs were examined by Dr S E W Smith, paediatric radiologist at St James's (University) Hospital. It was not possible to examine the films in true ignorance of the diagnosis as many of the children were well known from the time of the original injury. This was not considered to influence the assessment of the form, site, and dimensions of the fracture, which were recorded from the radiographs in each case.

Photographs, drawings, and written reports of necropsies performed by Professor D J Gee and Dr M A Green provided similar detailed information for each fracture case. Maximum fracture width was measured directly from the appropriate view radiograph but was not routinely recorded at necropsy.

\section{Results}

The usual excess of boys was noted in both groups. The bulk of abuse occurred in the first 6 months of life, the second and third months together providing 11 cases $(38 \%)$. The bulk of accidents occurred in the second 6 months with 28 cases $(47 \%)$.
Definitions. Terms used to describe skull fractures include the following:

Single linear-a fracture consisting of an unbranched line in straight, zigzagged, or angled configuration.

Multiple or complex-two or more distinct fractures of any type or a single fracture with multiple components. Branched linear fractures are included in this category.

Depressed-a fracture where the normal curvature of the skull is interrupted by inward displacement of bone. The term includes small punched in areas of inner or outer skull table or longer segments with surrounding fracture lines.

Growing-an enlarged linear fracture.

Maximum fracture width-the widest point of separation of a linear fracture measured on the radiograph most closely approximated to the fracture. In practice, the slight magnification resulting from viewing the fracture from the opposite side of the skull has an insignificant effect.

The anatomy of skull fracture in abuse and accident is described in Table 1 . Single linear fracture was the predominant injury in the accident group with considerably fewer cases after abuse. Most commonly parietal in site, the fracture extended to reach one or two sutures in most cases (Fig. 1).

In three children the fracture was bilateral and symmetrical in both parietal bones. One child was abused, another injured accidentally, and in the third subsequent abuse occurred. Bilateral linear fractures therefore present difficulties in assessment and should be interpreted with caution. They cannot be taken as certain evidence of abuse but should encourage careful assessment.

The multiple or complex fracture configuration (Fig. 2) discriminates strongly in favour of abuse: there were 23 cases compared with only three after accidents. Children with many fractures had shattered skulls and severe head injuries. The criss-cross pattern seen in some radiographs was reminiscent of crazy paving and should alert the doctor to the likelihood of abuse (Fig. 2).

Depressed fracture was also found appreciably more often in abuse. Only three children sustained

Table 1 Anatomy of skull fracture

\begin{tabular}{lll}
\hline Skull fracture & Accident $(n=60)$ & Abuse $(n=29)$ \\
\hline Single linear & 55 & 6 \\
Multiple complex & 3 & 23 \\
Depressed & 3 & 12 \\
Maximum width at & & 10 (of 13) \\
$\quad$ presentation $>3.0 \mathrm{~mm}$ & 4 & 6 \\
\hline
\end{tabular}




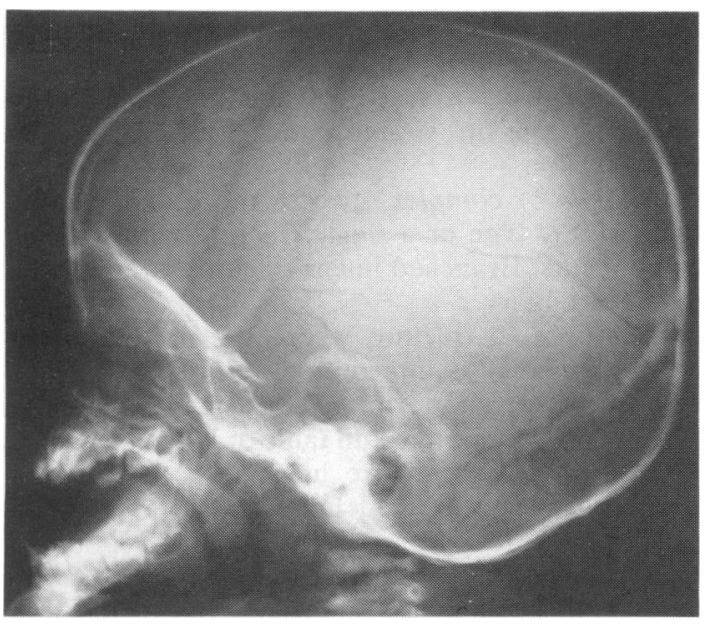

Fig. 1 Lateral skull $x$-ray showing a single linear parietal fracture in a child of 21 months who fell downstairs. The fracture is narrow $(1.0 \mathrm{~mm})$ and limited by coronal and lambdoid sutures. There were no other injuries in this genuine accident.

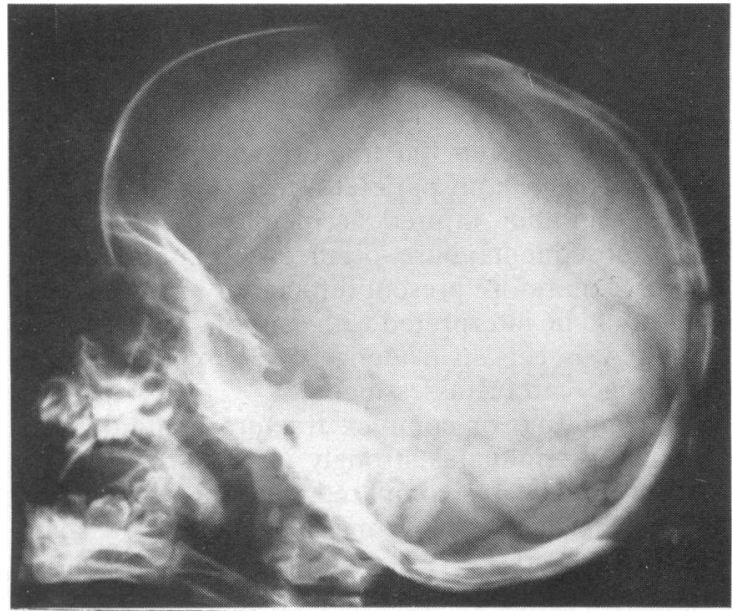

Fig. 2 Lateral skull $x$-ray of an 11 month old baby who allegedly fell off a settee. Multiple and complex fractures of the posterior skull produce a crazy paving effect. A wide $v$-shaped growing fracture extends posteriorly from the anterior fontanelle. The father ultimately admitted abuse.

depressed fractures after accidents and all were parietal and minor, requiring no surgical treatment. A typical example was a 10 month old baby who fell on to the sharp corner of a radiator and sustained a localised depressed fracture measuring $0.6 \mathrm{~cm}$ in depth by $2.5 \mathrm{~cm}$ in diameter. The depressed fracture in all 12 abused children was part of a complex fracture with the depressed segment frequently central in position, suggesting the point of impact.

In three children multiple depressed areas suggested repeated blows. In 6 cases the fracture was parietal and in 6 occipital. A fatal outcome ensued in half of the parietal and in all of the occipital fractures, emphasising the severity of the injuries.

The maximum width of the fracture in 40 accidental cases was $1.0 \mathrm{~mm}$ or less; 14 measured 1.0 to $3.0 \mathrm{~mm}$ and four 3.0 to $5.0 \mathrm{~mm}$. None was wider than $5.0 \mathrm{~mm}$; two were not measured. In the abused children, 6 fractures measured more than $5.0 \mathrm{~mm}$ on first presentation. A further four were between 3.0 and $5.0 \mathrm{~mm}$ and three between 1.0 and $3.0 \mathrm{~mm}$. None was $1.0 \mathrm{~mm}$ or less. Measurements were not available from necropsies of 16 children, although in two the pathologist commented that the fracture seemed to be excessively wide. It is possible that the condition at necropsy would not have reflected that in life.

Growing or expanding skull fractures are considered to be uncommon and are almost unknown after the first few years of life. There are many in the published reports, but the exact mechanism of their production remains incompletely understood. The essential features as stated by Lende and Erickson ${ }^{2}$ are:

(1) A skull fracture in infancy or early childhood.

(2) Dural tear at the time of injury.

(3) Brain injury beneath the fracture.

(4) Subsequent enlargement to form a cranial defect.

In this study, fractures more than $5.0 \mathrm{~mm}$ wide were considered to be growing, and details are given in Table 2-two followed accidents and 6 followed abuse. In the two accident cases and in four of the 6 abuse cases continued growth was noted after first presentation (Fig. 3), but in two cases of abuse a rapidly fatal outcome prevented follow up. In all cases symptoms, signs, or computed tomography (CT) findings provided evidence of brain injury. Surgical treatment to date has been undertaken in the three children with very large cranial defects. In one child a subdural haematoma was drained but the fracture continued to grow.

Site. The site of the skull fractures is shown in Table 3 . The parietal was the most commonly affected bone in both abuse and accident, in agreement with the findings of Harwood-Nash $e^{t} a l^{3}$ in 1189 skull fractures in children of all ages. Only four accidental fractures affected non-parietal bones. One fracture, which extended from the parietal to the temporal bone, including the petrous portion, followed a fall of four metres from a first floor window. Three 
Table 2 Growing skull fracture

\begin{tabular}{|c|c|c|c|c|c|c|}
\hline $\begin{array}{l}\text { Age at time of } \\
\text { injury (mth) }\end{array}$ & Cause & Site & Size $(\mathrm{mm})$ & Symptoms & $C T$ scan findings & Outcome \\
\hline 4 & Fell from pram & R Parietal & $75 \times 25$ & $\begin{array}{l}\text { Swelling } \\
\text { Convulsions }\end{array}$ & $\begin{array}{l}\text { Shift of ventricle. } \\
\text { Low density defect }\end{array}$ & Repair at 22 months \\
\hline 7 & $\begin{array}{l}\text { Dropped } \\
\text { downstairs }\end{array}$ & L Parietal & $100 \times 60$ & $\begin{array}{l}\text { Hemiparesis } \\
\text { Swelling }\end{array}$ & & Repair at 17 months \\
\hline 2 & Abuse & R Parietal & $135 \times 25$ & $\begin{array}{l}\text { Swelling } \\
\text { Convulsions }\end{array}$ & $\begin{array}{l}\text { Normal ventricle. } \\
\text { Underlying haematoma }\end{array}$ & Repair at 3 months \\
\hline 11 & Abuse & L Parietal & $150 \times 12$ & Squint & $\begin{array}{l}\text { Large ventricle. CSF } \\
\text { collection beneath fracture }\end{array}$ & Follow up \\
\hline 1 & Abuse & L Parietal & $70 \times 8$ & None & Haematoma and swelling & Follow up \\
\hline 15 & Abuse & R Parietal & $100 \times 14$ & Coma & $\begin{array}{l}\text { Subdural haematoma and } \\
\text { cerebral oedema of } \mathbf{R} \text { hemisphere }\end{array}$ & Died \\
\hline 4 & Abuse & L Parietal & $105 \times 6$ & Coma & Subdural haematoma & Died $<12$ hours \\
\hline 3 & Abuse & Occipital & $105 \times 15$ & $\begin{array}{l}\text { Conjugate eye } \\
\text { deviation } \\
\text { Blindness }\end{array}$ & $\begin{array}{l}\text { Cerebral infarction and } \\
\text { haemorrhage in occipital region. } \\
\text { Subdural haematoma }\end{array}$ & Follow up \\
\hline
\end{tabular}
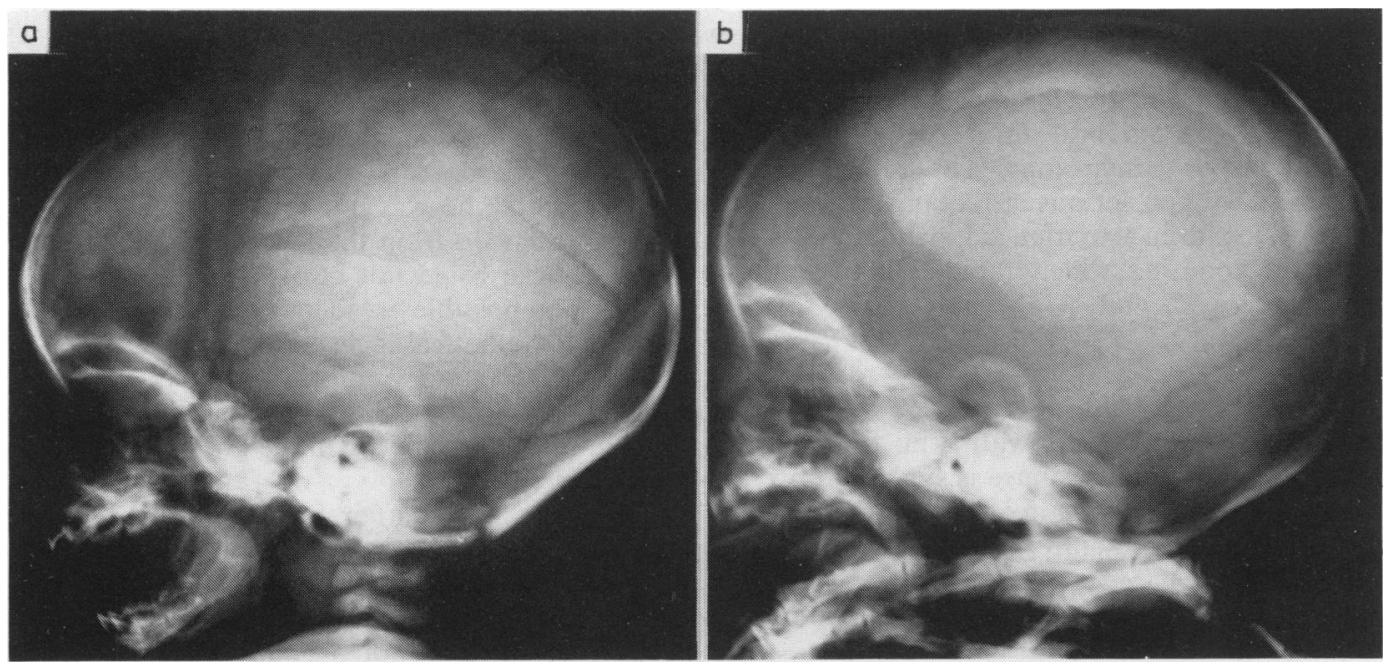

Fig. 3 Lateral skull $x$ ray (a) at presentation at 7 weeks of age and (b) at 13 weeks. Extensive horizontal growing fracture measuring (a) $11.0 \mathrm{~mm}$ and (b) $26.0 \mathrm{~mm}$. Multiple fractures and bruises of differing ages confirmed abuse.

Table 3 Site and extent of cranial fracture

\begin{tabular}{lcc}
\hline & Accident $(n=60)$ & Abuse $(n=29)$ \\
\hline Parietal & 57 & 27 \\
Occipital & 3 & 16 \\
Frontal & 0 & 4 \\
Temporal & 1 & 5 \\
Anterior/middle cranial fossae & 1 & 4 \\
Number of bones involved & & \\
1 & 56 & 7 \\
2 & 3 & 11 \\
3 or more & 1 & 11 \\
\hline
\end{tabular}

Figures refer to number of cases. occipital fractures resulted from falls downstairs. In two, the fracture was short $(3.0 \mathrm{~cm})$, narrow $(1.0$ $\mathrm{mm}$ ), linear, and uncomplicated. The third child was dropped from the mother's arms down three stone steps and sustained two fractures-one occipital and one parietal, both uncomplicated and $2.0 \mathrm{~mm}$ in width. No non-parietal fracture followed a fall to the floor from a chair, settee, or adult's arms. In cases of abuse there were many fractures of non-parietal bones, notably the occipital. Fractures of the thick bones of the anterior and middle cranial fossae as well as the temporal and frontal bones were also more common after abuse. 
A further measure of the extent and severity of the fracture is the number of bones involved. The infant's skull consists of distinct cranial bones separated by sutures. Table 3 shows that fractures rarely cross suture lines in accident cases but they do in cases of abuse.

Intracranial injury. In this series, all 20 deaths (19 abuse, one accident) resulted from intracranial injury, many before medical help was reached. Seven cases of subdural haematoma (6 in fatal abuse) received treatment. An additional 8 children sustained subdural haemorrhage of variable size. No case of subdural haematoma was detected in the accidental fractures.

Of the 10 survivors of abuse five had serious intracranial injury (one hemiparesis, one posttraumatic hydrocephalus, one convulsions, one cerebral infarction and subdural haematoma, and one extensive CT scan abnormalities). The accident group fared better with a single death after an extradural haemorrhage in a 6 month old child who fell out of his pram. In two children with growing fractures, underlying cerebral injury resulted in focal motor signs or convulsions. The remaining children escaped with no serious intracranial injury, although a few children experienced symptoms of drowsiness and vomiting which rapidly improved after admission to hospital.

\section{Discussion}

In children aged under 2 years with skull fracture after alleged minor accidents, abuse is suggested by one or more of the following features:

Multiple or complex fracture

Depressed fracture

Maximum fracture width greater than $3.0 \mathrm{~mm}$ Growing fracture

Involvement of more than a single cranial bone Non-parietal fracture

Associated intracranial injury.

The more features present, the more confidently can abuse be diagnosed. In support of this, it was found that 47 of the 60 accident cases exhibited none of these features whereas 24 of 29 cases of abuse had more than two. The remaining 13 accident cases had from one to three features, with an appropriate history to explain the more severe injury in 10 . In the remaining three children, who were all dropped, the diagnosis of accident must now be viewed with some uncertainty, especially as one child was later abused.

These conclusions are dependent on the effectiveness of separation of abuse from accident. No grey area of diagnosis has been formally defined in this study, although it would be unwise to claim that abuse could be confidently distinguished from accident in every case. Those cases where doubt existed have been included in the accident group.

The diagnosis of abuse demands absolute certainty to avoid conviction of innocent parents and unwarranted removal of children from their homes. The evidence must satisfy both the needs of clinical diagnosis and the process of law. The two most important corroborative facts in the diagnosis of abuse were the presence of multiple injuries and an inadequate explanation for the injuries.

It is fortunate that after abuse parents invariably gave a history of a minor fall or accident and did not claim that major incidents had been responsible for the child's injuries. Examples of the histories offered were: 'the baby slipped into the bath', 'he rolled off the settee', 'I dropped him into his pram, catching his head on the side'. Additional accidents were often added later when it was pointed out that the child had multiple injuries.

The 15 accident cases referred to the child abuse team reflect a reasonable level of suspicion of abuse among the doctors caring for these children. Only one child, who was not referred to the abuse team, was excluded from the study because serious doubts of abuse could not be resolved. While it is obviously not possible to identify missed cases of abuse, the hypothetical inclusion of a small number in the accident group would be unlikely to affect the overall conclusions, which are based on highly significant differences between the groups for all the features described.

What is the explanation for the differences in skull fracture in the two groups? The only information relating the severity of an accident to the resulting injury comes from clinical studies, as experimental work is not available. Helfer $e t a l^{4}$ studied the injuries sustained by infants and children aged under 5 years who fell from beds, cots, or hospital trolleys where the height did not exceed 90 $\mathrm{cm}$ (35 inches) and where the history was reliable and abuse had been excluded. In 264 children only two skull fractures were found, and none had serious intracranial injury. The skull fractures were linear and narrow. Kravitz et $a l^{5}$ studying infants in the first year of life recorded 330 falls, mostly from beds, couches, dressing tables, and cots: only three skull fractures and one subdural haematoma were found. The results of the present study broadly agree with those of earlier ones-only one child sustained a skull fracture after a fall from a height of less than $3 \mathrm{feet}(91 \mathrm{~cm})$ and this was linear, narrow, and uncomplicated.

While acknowledging the difficulties of assessing 
clinical histories in retrospect, most accidental fractures seemed to result from moderate falls of between 3 feet $(91 \mathrm{~cm})$ and 5 to 6 feet $(152$ to 183 $\mathrm{cm})$. Examples were falls from baby chairs placed on tables and from standing adults' arms. Skull fracture seems more likely to occur in this situation but again will be linear, narrow, and uncomplicated. Accelerated falls when mobile children run, climb, and play are difficult to equate with gravitational falls in babies but are seldom severe. More severe accidents such as falls downstairs or from heights of greater than 6 feet $(183 \mathrm{~cm})$ resulted in injuries where one or two 'abuse-type' features might be present.

The most severe fractures all followed abuse and must imply severe injury. In episodes of battering, substantially greater force is involved than that which occurs in the usual domestic accident. The only equivalent injuries after accidents that we have seen have been in children run over by motor vehicles.

Several of the features linked with abuse require further elaboration. The measurement of maximum fracture width in this age group is strongly recommended as an important pointer to abuse. Though it is possible that skull fractures widen with time, all those which presented with scalp swelling after variable delays were less than $3.0 \mathrm{~mm}$ in width. Maximum fracture width probably relates to other factors including the severity of the injury.

In some instances, occupation of intracranial space by oedema, ventricular enlargement, or blood produced fracture separation as an alternative to suture widening, which was infrequently seen. It has been suggested that an acute rise in intracranial pressure at the time of injury might be responsible for the bursting fracture. ${ }^{6}$ The mechanical process involved, however, has yet to be determined.

Dural tear and underlying cerebral injury are antecedents of the growing fracture, which in this study has important associations with abuse. A review of several papers in the English language $^{27-13}$ showed more than 50 cases of growing. fracture but only two cases where the stated mode of injury was child abuse. The findings in this study, that is, 6 cases of abuse and two of accident, conflict with earlier reports.

Growing fractures have attracted the attention of. neurosurgeons and radiologists more than that of paediatricians, and their reports have focused on pathogenesis and surgical management rather than on their cause. This may explain some of the differences. A final observation is that growing fractures follow severe injury, and both cases due to accidents involved major falls. The presence of a growing fracture, where a minor fall is alleged, is likely to be the result of abuse.
Depressed fractures are very uncommon in the 0 to 6 month old child except after birth trauma, ${ }^{3}$ which in most maternity units nowadays has become a rarity. This type of fracture should arouse strong suspicion of abuse if the history does not positively implicate a fall onto a sharp or pointed object. A depressed fracture of the occipital bone is virtually pathognomonic of abuse, and the prevalence of occipital fractures in general may reflect the position in which the child is held as his head is struck against a wall or other solid object.

This study also confirms the important-connection between subdural haematoma and abuse. The absence of a single case of clinically detected subdural haematoma after accident is remarkable. The high incidence of brain injury and death in abused children is a further reflection of the severity of the head injury but there is nothing specific in the type of injury.

Many of the children described here represent the severe end of the spectrum of skull fracture in abuse. It is possible that more 'gently battered babies' might be indistinguishable from those having minor falls. Single, linear, parietal fractures do follow abuse, but in three of the four cases in this series there were other features that would have indicated abuse (two wide fractures and one subdural haematoma).

This study provides guidelines for the detection of abuse in children with skull fracture. It should assist in the protection of the seriously injured abused child and enable the professional witness to pronounce with greater confidence on this difficult injury.

I thank Dr Michael Buchanan for advice and encouragement throughout this study. I also thank Dr Sidney Smith, Mr Nigel Smeeton, Dr Chris Chan, and Dr Michael Green for their help; the paediatricians, paediatric, orthopaedic, and neurosurgeons who gave permission to study the children in their care; Miss Lynne Hawkins and Mrs Wendy Pearson for secretarial help; and Professor Roy Meadow for invaluable assistance in reviewing the manuscript.

\section{References}

${ }^{1}$ Ellis M. Fractures of the parietal bone in children. Lancet 1958;i:1048-9.

2 Lende RA, Erickson TC. Growing skull fractures of childhood. J Neurosurg 1961;18:479-89.

3 Harwood-Nash DC, Hendrick EB, Hudson AR. The significance of skull fractures in children. Radiology 1971;101:151-5.

${ }^{4}$ Helfer RE, Slovis TL, Black M. Injuries resulting when small children fall out of bed. Pediatrics 1977;60:533-5.

5 Kravitz H, Driessen G, Gomberg R, Korach A. Accidental falls from elevated surfaces in infants from birth to one year of age. Pediatrics 1969:44:Suppl:869-76.

6 Klein DM. Central nervous system injuries. In: Ellerstein NS, ed. Child abuse and neglect. A medical reference. New York: J Wiley \& Sons, 1981:76.

${ }^{7}$ Kingsley D, Till K, Hoare R. Growing fractures of the skull. J Neurol Neurosurg Psychiatry 1978;41:312-8. 
${ }^{8}$ Rothman L, Rose JS, Laster DW, Quencer R, Tenner M. The spectrum of growing skull fracture in children. Pediatrics 1976;57:26-31.

9 Kuhns LR, Nelson D, Deibert G. Transillumination detection of a growing skull fracture. Am J Dis Child 1977;131:889-92.

10 Thompson JB, Mason TH, Haines GL, Cassidy RJ. Surgical management of diastatic linear skull fractures in infants. J Neurosurg 1973;39:493-7.

11 Vas CJ, Winn JM. Growing skull fractures. Dev Med Child Neurol 1966;8:735-40.

12 Taveras J, Ransohoff J. Leptomeningeal cysts of the brain following trauma with erosion of the skull: study of seven cases treated by surgery. $J$ Neurosurg 1953;10:233-41.

13 Stein BM, Tenner MS. Enlargement of skull fracture in childhood due to cerebral herniation. Arch Neurol 1972;26:137-43.

Correspondence to Dr C J Hobbs, Department of Paediatrics and Child Health, St James's University Hospital, Beckett Street, Leeds LS9 7TF.

Received 8 October 1983

Fifty years ago

Sensitivity to cows' milk proteins in acute gastroenteritis

K H TAllerman (The London Hospital)

\section{Conclusions}

'It appears from the experiments carried out that reagins to cows' milk proteins are frequently present in the blood of infants suffering from gastro-enteritis. From this one may conclude that many such infants are hypersensitive to cows' milk proteins.

It is possible that some of the toxic symptoms of acute gastro-enteritis may be in the nature of an allergic reaction. 